\title{
MODERN METHODS OF PARACHUTE RESCUE SYSTEM TESTING
}

\author{
J. Pejchar*, T. Hájek ${ }^{* *}$
}

\begin{abstract}
This paper presents an improved free-flight testing method applicable to parachute systems used by rescue systems. The method as described allows parachute testing in the speeds and for payloads over the limits acceptable for available testing platforms. Based on an algorithm with the approach for achieving demanded speed, it also includes a design of instrumented parachute testing vehicle. Both methods with the algorithm and testing vehicle were evaluated by airdrop tests and their features have been successfully proved..
\end{abstract}

\section{Keywords: parachute, rescue system, testing}

\section{Introduction}

Modern piloted aircrafts, as well as unmanned vehicles, are designed with an accent to the maximal safety of its crew and its own. Aircrafts use various active and passive safety features. One of the most prominent is rescue system based on a parachute. The main advantage of the rescue system is the capability to deliver entire aircraft safely from the sky back to the ground with minimal impact for the entire airframe and its crew.

Parachutes used for rescue systems are fundamentally different in comparison to military or the spacecraft parachutes. The key difference is the requirement for parachute deployment at minimal possible altitude and for speed range from stall speed to design diving speed.

\section{Parachute rescue system requirements}

The Importance of minimal altitude of deployment is clearly shown in Figure 1. Figure collects rescue system activations recorded by the biggest world parachute rescue system producers (BRS from the USA and Galaxy GRS from the Czech Republic). By the end of 2017, these companies saved already 488 lives from the aircrafts with a range from $90 \mathrm{~kg}$ up to $2150 \mathrm{~kg}$. The majority of the accidents happened close to the airfields during take-off and landing maneuvers. As may be seen below $60 \%$ out of all recorded events occurred under altitude $150 \mathrm{~m}$ and $73 \%$ were under $300 \mathrm{~m}$.

Rest of recorded events happened in altitude over $300 \mathrm{~m}$. These events happened in a speed range from stall speed to design diving speed. This range is growing mainly in higher speed end of flight envelope as manufacturers are increasing the performance of today planes.

\section{Parachute rescue systems testing}

The main parts of rescue system (ejecting mechanism and parachute) are usually tested separately. Ejecting mechanism is tested to prove its capability to deliver parachute and all of its parts (canopy, slider, suspension lines, riser, etc.) out of airframe and out of the possible aerodynamic wake, as fast as possible.

On the other hand, parachute testing is much more complex. During tests, functionality, behavior, and performance are closely observed. The reason is the fact that test results strongly influence the parachute

\footnotetext{
* Ing. Jan Pejchar: Institute of Aerospace Engineering, Brno University of Technology; Technická 2896/2; 616 69, Brno; CZ, pejchar@fme.vutbr.cz

** Ing. Tomáš Hájek: Institute of Aerospace Engineering, Brno University of Technology; Technická 2896/2; 616 69, Brno; CZ.
} 


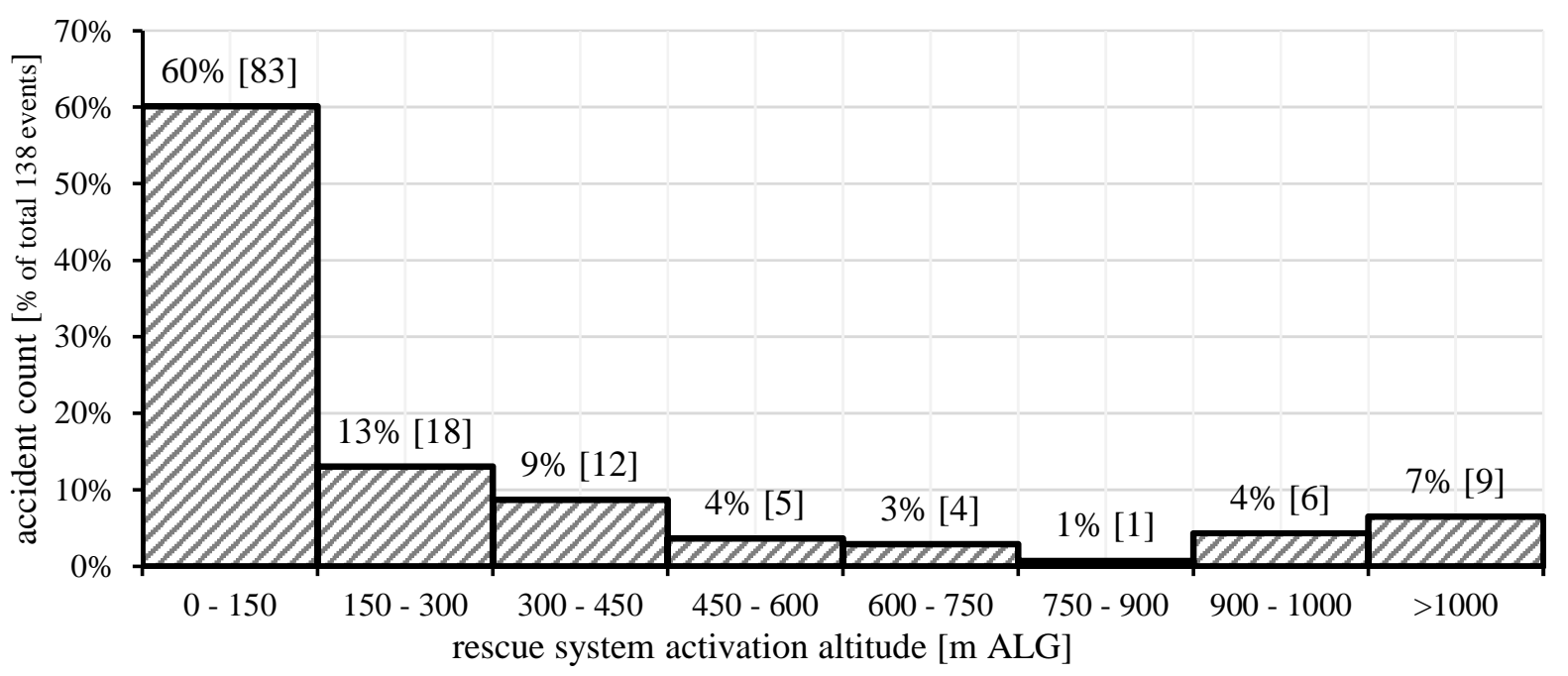

Fig. 1: Parachute rescue systems activation records see online Galaxy GRS (2017) and BRS (2017)

design (from materials selection, sewing up to packing). Therefore it is hard to estimate all design needs before the first test. Before parachute is set for operation in the aircraft, has to prove its capability to meet all regulation requirement. Regarding to regulation requirements as set by ASTM F2316, the most sufficient and commonly used method is the full-scale free-flight testing. This method is also referred by the Knacke (1992) and Maydew (1991) and allows observation and measurement of performance, stability, flight trajectory, the rate of descent, drift tendencies, and other phenomena. Free-flight test methods use unpowered IPTV (Instrumented Parachute Test Vehicle). IPTV for this tests is equipped with sensors and data acquisition unit. All sensors should be synchronized in time and logged for after-test evaluation. Such option discuss Drahanský (2009). When IPTV is released from stationary or moving aerial platform the parachute opening process is immediately activated. Parachute test conditions are then the same as a condition of the aerial platform had at the time of release.

\section{Free-flight method limits extension}

Limits of the free-flight testing method are set by the maximal speed and maximal payload capacity of the stationary or moving aerial platforms used for testing. Limits can be extended when aerial platform with high payload capacity is used and IPTV is accelerated by the effect of the gravity force after release.

Figure 2 presents where are the limits of recently available platforms registered under CAA (Czech Aviation Authority) and how can be these limits extended. Subsequently, the graph presents weight and speed maximums of recently manufactured and install parachutes and specify an area of upcoming market interest. It is clearly visible that free-flight method can not cover parachute rescue systems as required by the market.

When IPTV is accelerated by the effect of the gravity force the deployment of the parachute may be governed actively by current speed or current altitude evaluation, or passively by time. Active control is demanded in terms of overall complexity (computational power, dimensions, data sample rate, etc.). Passive control beats disadvantages of active control. On the other hand, it requires precise mathematical model describing IPTV moving in time and determining the time needed for reaching the desired speed.

\section{Mathematical model}

The mathematical model used in this method is based on numerical integration of equations of motion. Model is simplified for movement of the mass point in two dimensions, including the model of the atmosphere and incorporates its effects. This model is then brought to the algorithm which output is the duration of gravity free-flight test. Figure 3 shows algorithm roadmap.

The algorithm consists of two control loops, which ensure that test conditions are met and altitude for system deceleration sufficient - by experience at least $250 \mathrm{~m}$ AGL. The algorithm also incorporates delay time for the beginning of parachute deployment sequence. 


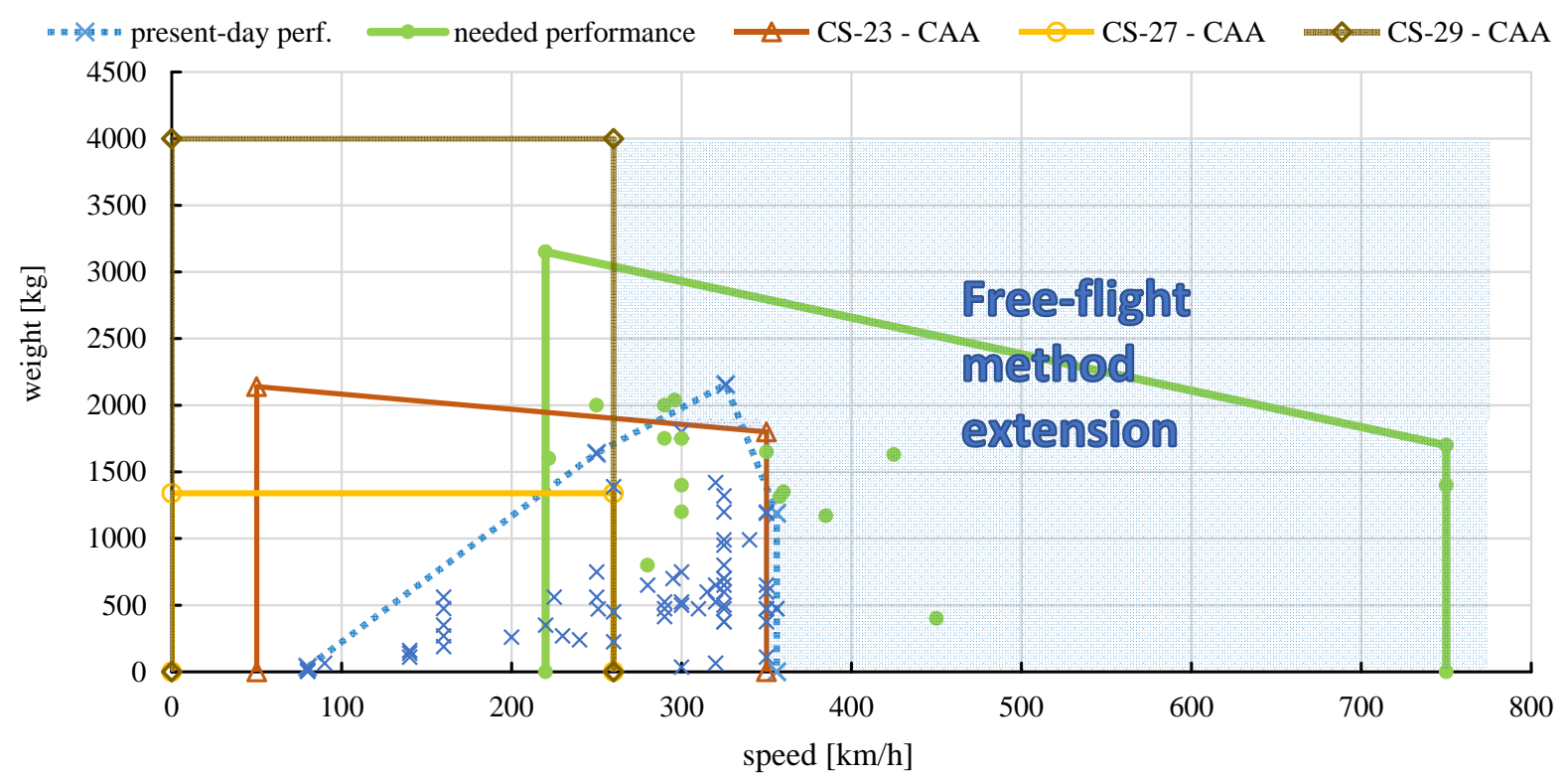

Fig. 2: Testing aerial platforms and parachute performance envelope. See online Galaxy GRS (2017), BRS (2017) UCL (2011).

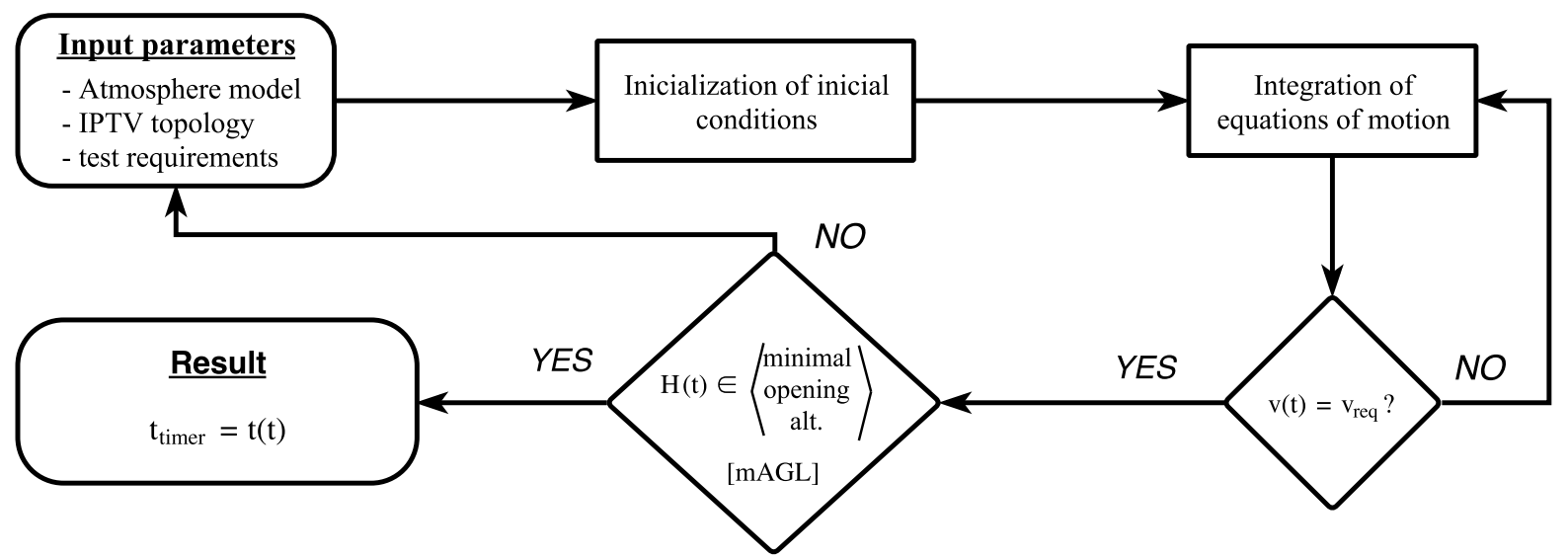

Fig. 3: Free-flight extension method algorithm for the duration of gravity boost.

\section{Verification of the method}

Tests were conducted to prove the possibilities of the described approach. Moving platform was used to conduct these test. Following Initial conditions, as on the test field, were set up into the algorithm: temperature on ground: $17^{\circ} \mathrm{C}$; pressure on ground $95550 \mathrm{~Pa}$; release altitude: $1100 \mathrm{~m}$ AGL; demanded speed of parachute use: $380 \mathrm{~km} \mathrm{~h}^{-1}$ EAS (Equivalent Air Speed to 0m International Standard Atmosphere); speed of platform: $150 \mathrm{~km} \mathrm{~h}^{-1}$ IAS (Indicated Air Speed).

Algorithm results were as follows: at time $12,5 \mathrm{~s}$ the speed of $380 \mathrm{~km} \mathrm{~h}^{-1}$ EAS is reached $\left(=399 \mathrm{~km} \mathrm{~h}^{-1}\right.$ IAS), at the $388 \mathrm{~m}$ AGL, timer setting: $11,7 \mathrm{~s}$. This setup was then programmed into IPTV and gravity boosted drop test was performed.

Figure 4 shows the altitude and speed as a function of time can be seen. Significant time points are marked as follows: 1 - IPTV releases from aircraft (speed sensors affected by propeller wash); $2-11,7 \mathrm{~s}$ mark start of the main parachute deploy sequence; 3 - main parachute fully deployed, maximum speed $375 \mathrm{~km} \mathrm{~h}^{-1}$ EAS; 4 - parachute fully inflated, gradual deceleration to steady state descent

Please note, that acceleration of IPTV took $12,8 \mathrm{~s}$ - at that point of maximum speed $405 \mathrm{~km} \mathrm{~h}^{-1}$ IAS at the altitude of $530 \mathrm{~m}$ AGL. That is $385 \mathrm{~km} \mathrm{~h}^{-1}$ EAS which results in an error of $5 \mathrm{~km} / \mathrm{h}$ i.e. $1,2 \%$ compared to the demanded speed of parachute use. 


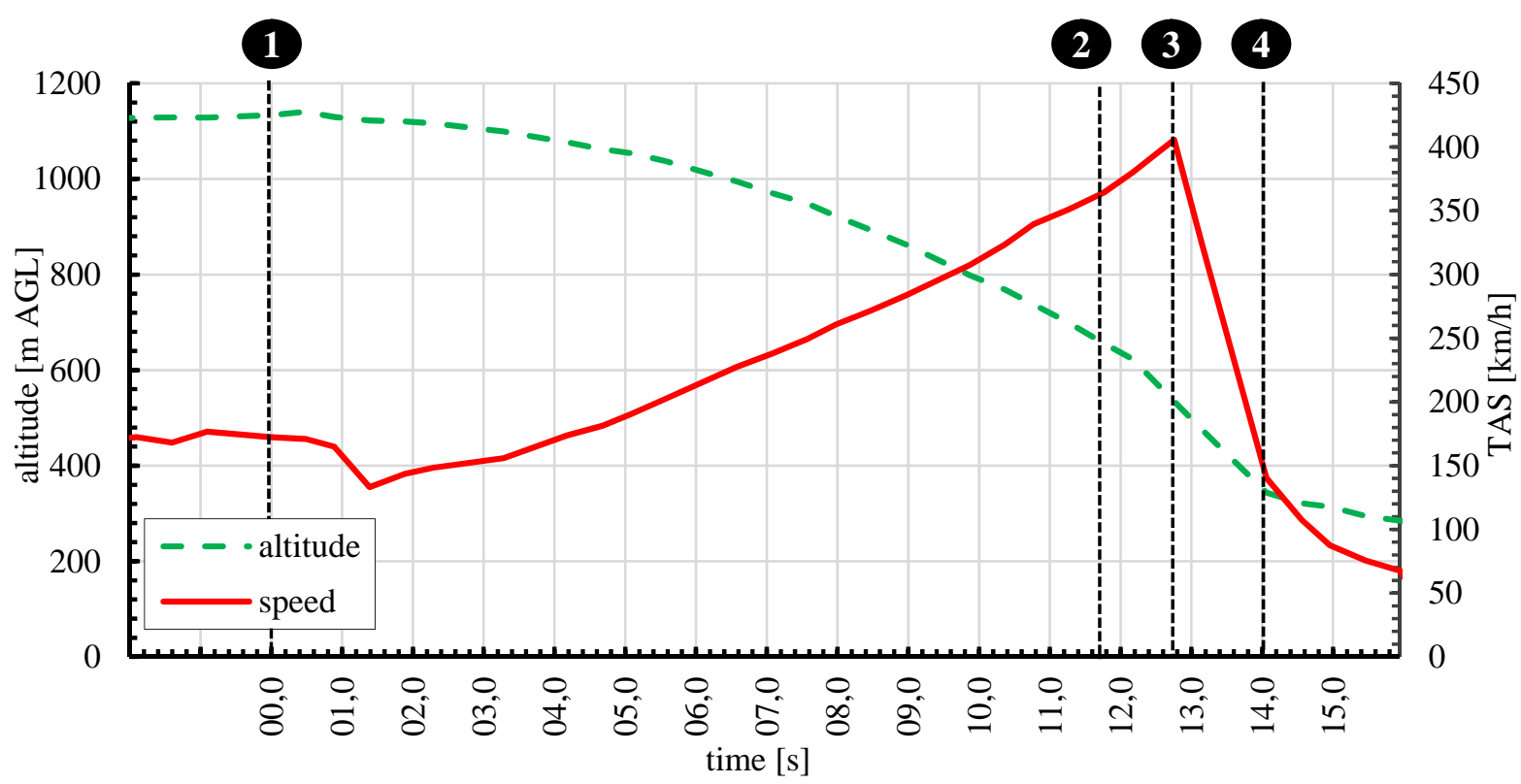

Fig. 4: Speed and altitude log file from free flight test validation

\section{Conclusions}

Paper deals with the improvement of a free-flight testing method for parachute rescue systems. The method is based on the acceleration of test vehicle by gravity forces. Activation of main parachute deployment sequence is governed by the duration of gravity acceleration. Which on one hand proved as simple, reliable solution, on the other hand, demanded development of the mathematical model to determine the duration of acceleration.

To prove method concept a few full-scale free-flight tests were conducted. It showed the method as the reliable precise mean for parachute testing beyond the typical flight performance of CS-23 or CS-29 airplanes.

Further work is in gathering more test data that would confirm method precision and allowed to determine its accuracy. Incorporating more precise sensors with high logging frequency could be the way to obtain even more quality data.

\section{Acknowledgments}

The research leading to these results has received funding from the MEYS (Ministry of Education, Youth and Sports) under the National Sustainability Programme I (Project LO1202).

\section{References}

Drahanský, M. and Marvan, A. and Holenda, S. and Ppopela, R. (2009) Flight Data Wireless Digital Acquisition System. Letecký zpravodaj, Vol 2008, No. 2, pp. 15-17. ISSN: 1211-877X.

Knacke, T. W. (1992), Parachute recovery systems: design manual. Santa Barbara, CA: Para Pub. ISBN 09-155-16853.

Maydew, R.C. and Peterson, C.W. (1991). Design and testing of high-performance parachutes. Neuilly sur Seine, France: AGARD. ISBN 92-835-0649-9.

BRS aerospace BRS AEROSPACE TM , Web. 25 Jan 2017. Retrieved from http://www.brsaerospace.com/ Galaxy GRS GALAXY HOLDING s.r.o., Web. 15 Jan 2017. Retrieved from http://www.galaxysky.cz/ Civil Aviation Authority Civil Aviation Authority, Web. 4 Jan 2017. Retrieved from http://www.caa.cz/ 